\title{
Topic: A Comparative Study between Conventional and Endoscopic Dacryocystorhinostomy
}

\author{
Dr.Vivek Kumar Pathak ${ }^{1,}$ Dr.(Prof.) Debajit Das ${ }^{2,}$ Dr.Uttal.Taranga.Bhuyan ${ }^{3,}$ \\ Dr.Pinpo Teron ${ }^{(4)}$ \\ 1Corresponding author, PGT, department of otorhinolaryngology Assam Medical College, Dibrugarh, Assam \\ 2 Prof. and Head department of otorhinolaryngology Assam Medical College , Dibrugarh, Assam \\ 3 Assoc. Prof., department of otorhinolaryngology Assam Medical College, Dibrugarh, Assam \\ 4 Assist. Prof., department of otorhinolaryngology Assam Medical College, Dibrugarh, Assam
}

\begin{abstract}
Introduction: Dacryocystorhinostomy (DCR) has been the standard procedure for acquired nasolacrimal duct obstruction. Lacrimal sac can be approached (1) Conventional External (Ex-DCR) or (2) Endoscopic (EN-DCR)

Objective : To compare success rate, complication rate between the procedures

Materials and Methods: Study design, prospective, interventional, clinical study was conducted in department of otorhinolaryngology in conjuction with ophthalmology,AMCH, Duration of study: One year, from july 2011 to june 2012 , No. of cases : 60 cases(30 Endo-DCR,30 Ex-DCR). Data were analysed by graphpad prism version 6.01 for Microsoft, Independent-sample t test \&, chi square test with Yates correction was applied for comparison between groups, $P$ value of $<0.05$ was considered stastically significant .

Results and Observations : Total 60( 47 females, 13 males) cases randomised into 30( 27females, 3males) endoscopic dcr, 30(20females, 10 males) external dcr, Mean age (32.367)with range 18-55 yrs. in endoscopic $d c r$, Mean age (37.534) with range 16-66 yrs. in external dcr. Present study shows success rate of $86.67 \%$ for En-DCR \& 90\% for Ex-DCR with P-value 0.557

CONCLUSION : The present study clearly shows that En-DCR is having results comparable EX-DCR,
\end{abstract}

Keywords :

Keyword 1: En-DCR : Endoscopic Dacryocystorhinostomy

Keyword 2: Ex-DCR : External Dacryocystorhinostomy

Keyword 3: NLD : Nasolacrimal duct

\section{Introduction:}

Dacryocystorhinostomy (DCR) has been the standard procedure for acquired nasolacrimal duct obstruction, It is a procedure that involves creating a passage of lacrimal sac into nose bypassing nasolacrimal (nld) blockage , Lacrimal sac can be approached by (1) Conventional External (Ex-DCR) or by (2)Endoscopic (EN-DCR) Endoscopic DCR is a safe,fast, aesthetic procedure in 1904: Toti first described External DCR , $1893^{[2,3]}$ : Endonasal approach was first described by Caldwell Fiberoptic endoscope first used for Endo-DCR by Mc Dough \& Miring in $1989^{[4]}$ Endoscopic approach has renewed interest in past decade to correct primary and recurrent lacrimal obstruction, Objective : To compare success rate, complication rate between the procedures

\section{Materials and Methods :}

Study design, prospective, interventional, clinical study was conducted in department of otorhinolaryngology in conjuction with ophthalmology, $\mathrm{AMCH}$, Duration of study : One year, from july 2011 to june 2012, No. of cases : 60 cases(30 Endo-DCR,30 Ex-DCR), All the cases were examined by ROPLAS regurgitation test,syringing, probing ,DNE , 60 cases were having nasolacrimal duct obstruction and common canalicular obstruction were included into study, Inclusion criterion: All cases irrespective of age,sex having Epiphora, Acute on chronic dacryocystitis Chronic daryocystitis following nld ,cc block, Patients consenting for operation Exclusion criterion: Suspicion of malignancy, Post traumatic lid and bony deformity Noticeable lid laxity, No. of cases: 60 cases were included in the study as par inclusion criterion, In all the cases detailed clinical examination, Nasal endoscopy , X-ray PNS was done, 30 cases underwent endoscopic DCR \& 30 cases underwent external DCR under local anaesthesia \& medical treatment pre and postoperative ,1) Subjective improvement of symptoms : Fully satisfied,Partially satisfied,Not satisfied at all ,2) Anatomical Patency By Syringing Follow up was done in all cases at regular interval of I week,2weeks,3weeks,6weeks,3months and 6months ,Data were analysed by graphpad prism 
version 6.01 for Microsoft,Independent-sample t test \&, chi square test with Yates correction was applied for comparison between groups , $\mathrm{P}$ value of $<0.05$ was considered stastically significant .

\section{Results and Observations :}

Total 60( 47 females, 13 males) cases randomised into 30( 27females, 3males) endoscopic dcr, 30 ( 20females, 10 males) external dcr, Mean age (32.367 )with range 18-55 yrs. in endoscopic dcr, Mean age (37.534) with range 16-66 yrs. in external dcr.

Table No.1

Comparison Of Baseline Characteristics :

\begin{tabular}{|c|c|c|c|}
\hline & ENDOSCOPIC DCR & EXTERNAL DCR & P VALUE \\
\hline $\begin{array}{l}\text { (1) Total No. Of Cases } \\
\text { N }(\%)\end{array}$ & $30(50)$ & $30(50)$ & \multirow[t]{5}{*}{0.125} \\
\hline (2) Age (yrs.)(Mean+-S.D.) & 32.367 & 37.534 & \\
\hline \multicolumn{3}{|l|}{ (3) Gender } & \\
\hline Male & 4 & 10 & \\
\hline Female & 26 & 20 & \\
\hline
\end{tabular}

TABLE-2:COMPARING OUTCOME :

\begin{tabular}{|c|c|c|c|c|}
\hline SYRINGING & $\begin{array}{l}\text { ENDOSCOPIC } \\
\text { DCR }\end{array}$ & EXTERNAL DCR & P VALUE & $\begin{array}{l}\text { SATISFACTION } \\
\text { LEVEL }\end{array}$ \\
\hline PATENT N(\%) & $24(80 \%)$ & $26(86.67)$ & \multirow{4}{*}{0.557} & Fully Satisfied \\
\hline $\begin{array}{l}\text { Partial Block With } \\
\text { Clear } \\
\text { Regurgitation } \mathrm{N}(\%)\end{array}$ & $2(6.67 \%)$ & $1(3.34 \%)$ & & $\begin{array}{l}\text { Symptomatically } \\
\text { relieved therefore } \\
\text { satisfied }\end{array}$ \\
\hline \multirow[t]{2}{*}{ Complete Block N(\%) } & \multirow[t]{2}{*}{$4(13.34 \%)$} & \multirow[t]{2}{*}{$3(10 \%)$} & & \\
\hline & & & & $\begin{array}{lrr}\text { Not relieved } & \text { of } \\
\text { symptoms } & \text { so not } \\
\text { satisfied } & & \end{array}$ \\
\hline
\end{tabular}

TABLE 3 : AVERAGE TIME TAKEN FOR SURGERY :

\begin{tabular}{|l|l|l|}
\hline Procedure & Time take & P-Value \\
\hline En-DCR & 45 Miins. & 0.001 \\
\hline Ex-DCR & 75 Mins & \\
\hline
\end{tabular}

\section{COMPLICATIONS}

\section{Ex-DCR:}

Hypertrophied scar -2(6.67\%), closure of ostium-2(6.67\%)

En-DCR:

Nasal synechia formation-1(3.34\%), Granulation at ostium-1(3.34\%)

\section{IV: Discussion:}

Present study shows success rate of $86.67 \%$ for $\mathrm{En}-\mathrm{DCR} \& \mathrm{90 \%}$ for $\mathrm{Ex}$-DCR with P-value 0.557

\begin{tabular}{|l|l|l|l|}
\hline Series & En-DCR & Ex-DCR & P-Value \\
\hline Hatikainen et al (1998) & $89.1 \%$ & $90.2 \%$ & 0.914 \\
\hline Cokesser et al (2000) & $88.2 \%$ & $89.2 \%$ & \\
\hline S.Devis et al(1999) & $100 \%$ & $93.2 \%$ & \\
\hline
\end{tabular}


Revision surgery was done in all recurrent cases \& stenting done ,Stent removal done after 3 months, On follow up patients were patent on syringing \& symptomatically improved, Duration of surgery was approx. $\mathbf{4 5}$ mins in endoscopy DCR group as compared to 75 mins. in conventional external DCR group with $\mathbf{P}$ value of 0.01 which was statically significant, This was in conformity with study of J.Hartikainen (2003) with mean time 34.5 mins for external DCR and 18.5 mins. for endoscopic DCR with P value 0.0001

\section{Conclusion:}

The present study clearly shows that En- DCR is having results comparable EX-DCR , with added advantages of ,Aesthetic results with no external scar,Correction of associated nasal pathology, Preservation of lacrimal pump,Reduced operating time,Further research is needed in the subject.

\section{References:}

[1]. Rice D.H. Endoscopic Intranasal dacryocystorhinostoiny results in four patients. Arch. Otolaryngol. Head Neck Surgery; 116; 1061; 1990.

[2]. Caldwell. N.Y. Med. J., 57. 581; 1893.

[3]. Cokkeser Y. Evereklioglu C, Er H. Comparative external versus endoscopic dacryocystorhinostorny: results in 115 patients (130 eyes). Otolaryngology Head and Neck Surgery 2000; 123(4):488-491.

[4]. Nishi Gupta. Endoscopic Dacryocystorhinostomy: A Revolution, 2nd Edition.

Instruments used in endo-dcr :

Steps of endo-dcr
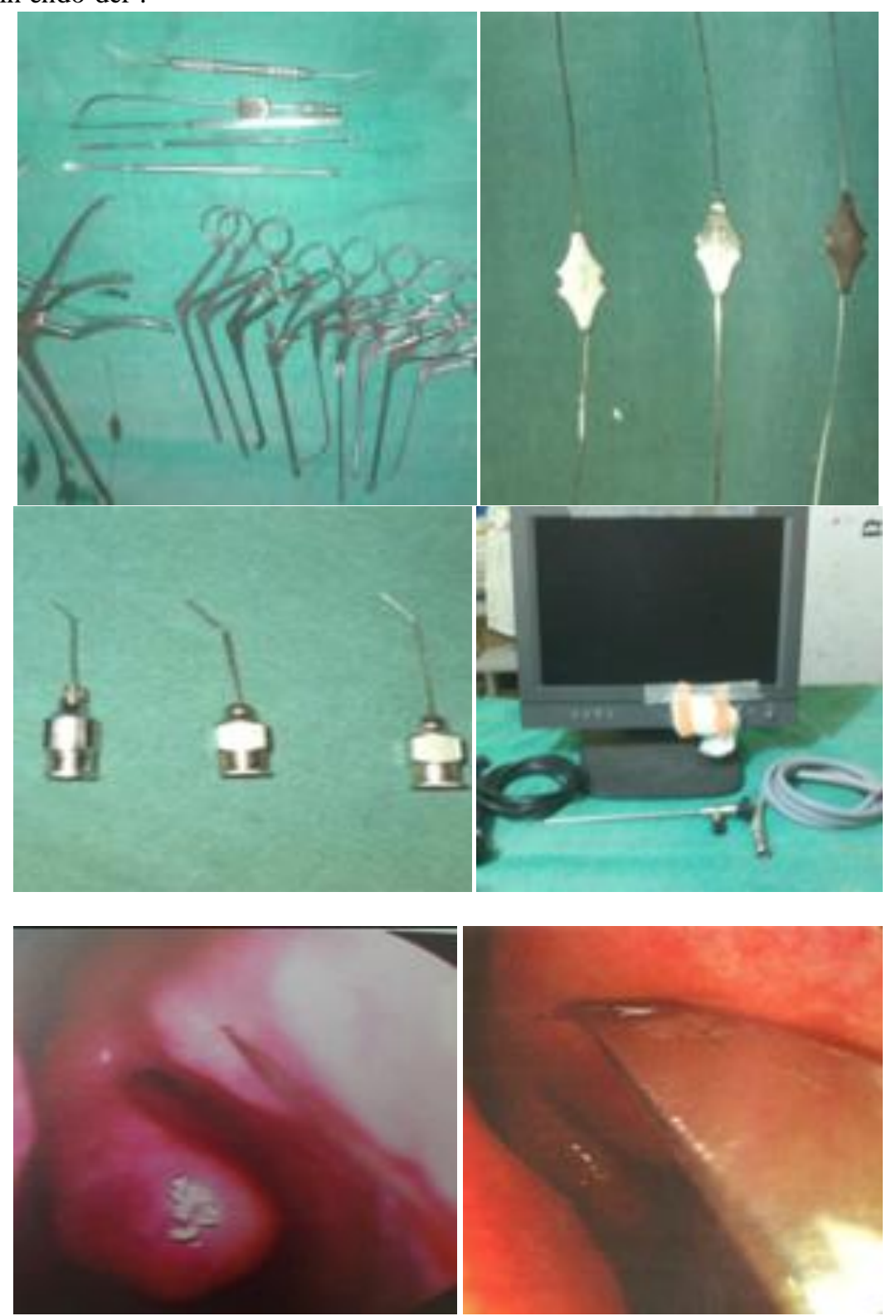